\section{References}

1. Dodonov V. N., Ermakov V. D., Krylova M. A. Big legal dictionary. Moscow: 2001. P. 790.

2. Shchekin D. M. On the crisis of justice in tax disputes. // Law. N 10. 2016. P.31-37.

3. Artemenko D. A. Improving the methodology of tax investigations to identify the risks of evasion of value added tax. // Actual problems of economic practice. V 8. №4 part 2. 2010 P. 51-60.
4. Martasov D. Disputes over the price of real estate in tax disputes. // Housing right. 2020, № 1. P. 35-43.

5. Zakharenkova E. V. Trends in the development of the concept of the actual right to income in judicial practice. // Taxes. N 1. 2020. P. 38-41.

DOI 10.6060/ivecofin.2020464.507

МЕТОДИКА ОЦЕНКИ ВЛИЯНИЯ РЕПУТАЦИОННОГО РИСКА

УДК 336 НА УСТОЙЧИВОСТЬ КОММЕРЧЕСКОГО БАНКА

Бибикова Екатерина Алексеевна, Курникова Ирина Валерьевна Ивановский государственный университет, ул. Ермака, 39, Иваново, 153025, Россия E-mail: eabibikova@mail.ru,kyrnik@mail.ru

В настоящее время в России, когда продолжается отзыв лицензий у кредитных организаций, значимость репутационных рисков резко возрастает. В связи $c$ этим предметом исследования в данной статье выступает репутационный риск и его влияние на поддержание устойчивости кредитной организации. Целью работы является разработка новой методики для оценки влияния репутационного риска на устойчивость коммерческих банков, а также практическое применение методики с использованием данных кредитной организации. В результате исследования была составлена определенная методика, которая позволяет проводить оценку непосредственно репутационного риска в коммерческом банке; определена взаимосвязь данного вида риска и устойчивости кредитной организации; применена методика на практике с использованием данных нескольких коммерческих банков; показано, как может влиять репутационный риск на устойчивость кредитной организации. Представленная статья позволяет определить, что необходимо понимать под репутационным риском, почему оценка репутационного риска имеет такую же важность, что оценка устойчивости кредитной организации, а также на что нужно обратить внимание руководителям кредитной организации, чтоб их банк имел удовлетворительный уровень репутационного риска, а, следовательно, и уровень устойчивости.

Ключевые слова: репутационный риск, коммерческий банк, методика оценки репутационного риска, устойчивость кредитной организации, управление репутационным риском

\title{
TECHNIQUE OF ASSESSMENT OF THE IMPACT OF A REPUTATIONAL RISK ON STABILITY OF COMMERCIAL BANK
}

Bibikova Ekaterina A., Kurnikova Irina V.

Ivanovo State University, Ermaka st., 39, 153025, Ivanovo, Russia

E-mail: eabibikova@mail.ru, kyrnik@mail.ru

At present, in Russia, when the revocation of licenses from credit organizations continues, the significance of reputational risks is growing sharply. In connection with this subject of research, reputational risk and its influence on maintaining the stability of a credit institution are presented in this article. The aim of the work is to develop a new methodology for assessing the impact of reputation risk on the stability of commercial banks, as well as the practical application of the method using data from a credit institution. As a result of the study, a specific methodology was compiled, which allows you to directly assess the reputation risk in a commercial bank; the relationship of this type of risk and the stability of the credit institution is determined; the methodology has been applied in practice using data from several commercial banks; It is shown how reputation risk can affect the stability of a credit institution. The presented article allows one to determine what is necessary to understand as reputational risk, why the assessment of reputational risk is of the same importance as the assessment of the stability of a credit institution, and what attention should be paid to the 


\section{leaders of a credit institution so that their bank has a satisfactory level of reputational risk, and there-} fore, and level of sustainability.

Keywords: reputation risk, commercial bank, assessment technique of a reputational risk, steadiness of credit institution, management of a reputational risk

В современных условиях полная или частичная потеря деловой репутации может негативно отразиться на основных показателях деятельности кредитной организации, вызвав отток клиентов и, как следствие, сокращение ресурсной базы, снижение объема размещенных средств в доходные операции, снижение уровня ликвидности, падение доходности и рентабельности банковского бизнеса.

Однако достаточно длительно время вопросам поддержания и управления деловой репутацией в системе управления рисками уделялось недостаточное внимание, что было связано со сложностью оценки влияния этого фрактора на финансовые показатели банка. Кроме того, репутационные риски сложно оценивать в краткосрочной перспективе, тогда как долгосрочное планирование деятельности кредитных организаций затруднялось нестабильностью на финансовых рынках.

Банк России в настоящее время уделяет достаточное внимание учету репутационного риска в деятельности коммерческих банков. Наряду с такими наиболее известными банковскими рисками как кредитный, рыночный, валютный, процентный риски, риск потери деловой репутации был включен в перечень типичных банковских рисков [1]. Этот риск определяется как вероятность возникновения убытков в результате уменьшения числа клиентов (контрагентов)по причине формирования в обществе негативного представления о финансовой устойчивости кредитной организации, качестве оказываемых ей услуг или характере деятельности в целом. Репутационный риск также может быть охарактеризован как некий набор рисков, возникающих в результате взаимоотношений компании, проблем с исполнением соответствующих законов, а также ущерба, нанесенного доверию к организации и ее репутации, которые угрожают в долгосрочном плане доверию, проявляемому к компании акционерами, клиентами, регулирующими органами, служащими и прочими контрагентами [2].

Обобщая имеющиеся в научной литературе определения, можно описать данный вид риска для коммерческого банка следующим образом: репутационный риск банка - это вероятность возникновения потерь по причине значительного ухудшения деловой репутации (гудвилла) изза воздействия внутренних и внешних фракторов, в том числе нарушения ею законодательства, а также по причине ее неспособности эффективно управлять разными видами рисков, противодействовать мошенничеству, что может повлечь за собой финансовые потери, потерю конкурентных преимуществ, а также вызвать риск потери ликвидности и даже полную потерю стоимости кредитной организации [3], [4].

Можно отметить, что ещё в 2005 г. Банком России было издано Письмо 92-Т «Об организации управления правовым риском и риском потери деловой репутации». В нём приводится перечень внешних и внутренних факторов, которые могут привести к потере деловой репутации.

Все фракторы по уровню объективности можно условно разделить на две группы: объективные и субъективные факторы.

Объективные фракторы связаны с практикой банковского дела и вызываются противоправной деятельностью, неисполнением договорных обязательств и тому подобными ситуациями.

Субъективные фракторы во многом обусловлены конфлликтом интересов между основными стейкхолдерами, к которым относятся собственники, клиенты контрагенты банка, служащие, регулирующие органы. Второй группе фракторов длительное время не уделялось достаточно внимания [5].

Таким образом, в связи со значимостью данного вида риска и его влиянию на все стороны деятельности банка необходима разработка методики оценки влияния репутационного риска на устойчивость кредитной организации. Данная методика подразумевает разработку целей и задач.

Целью создания методики является оценка репутационного риска.

В задачи данной методики входят следующие:

- выявление нарушений внутренних процессов банка и обоснование действий по их устранению;

- получение данных об уровне репутационного риска и тех процессах, внутри которых чаще всего и в большом количестве совершаются нарушения;

- формирование перечня мероприятий дляустранению нарушений, минимизации/оптимизации риска и дальнейшему недопущению подобных ситуаций.

- установление и оценка влияния уровня репутационного риска на устойчивость кредитной организации.

К сфрере практического применения методики можно отнести следующее [6], [7], [8], [9]:

- проведение слияний или поглощений. Зачастую деловая репутация (гудвилл) составля- 
ет существенную часть стоимости бизнеса. Компании, имеющую положительную деловую репутацию, могут стоить в несколько раз дороже, чем общая стоимость принадлежащего им имущества. Банковский бизнес не является исключением. В банковской практике считается, что при покупке банка возможна коррекция оценки его стоимости по сравнению со стоимостью собственных капиталов на более чем $30 \%$. К примеру, фрранцузский банк BNP Paribas в 2004 году приобрел российский банк «Русский стандарт» со стоимостью гудвилла порядка $60 \%$ от стоимости сделки;

- привлекательность инвестирования. Оценка деловой репутации - это один из способов доведения до инвесторов ценности банка, а, значит, и повышения его потенциальной стоимости;

- управление деловой репутацией. Оценка гудвила применяется также для качественного анализа созданного имиджа и репутации компании, а также проведения их корректировки в соответствии с долгосрочными целями кредитной организации;

- эффективность использования репутации. Гудвилл - это актив, который способен влиять на уровень прибыльности кредитной организации, что позволяет считать его конкурентным преимуществом компании. Отсюда делаем вывод, что оценка гудвилла необходима при анализе его влияния на уровень доходности;

- объективная оценка текущего состояния деловой репутации способствует принятию адеватных управленческих решений, в том числе, направленных на улучшение деловой репутации;

- определение доходности деловой репутации, то есть оценка той части прибыли, которая была получена сверх «обычных» заработков кредитной организации без положительного гудвилла;

- оценка финансовой устойчивости отдельного банка и влияние на банковский сектор отдельного региона.

Программа (содержание) методики:

1) Разработка и дополнение показателей, влияющих на деловую репутацию кредитной организации.

2) Оценка данных показателей.

3) Формирование итогового значения показателя репутационного риска.

4) Формулирование выводов по итогу оценки данного вида риска и влиянию его на устойчивость кредитной организации.

5) Составление рекомендаций по снижению репутационного риска.

Пользователями данной методики могут являться:

- сами кредитные организации в лице их руководящего состава,
- специализированные отделы банков по управлению и минимизации рисков;

- контролирующие органы, в т.ч. Центральный Банк РФ.

Разработанная методика подразумевает объединение в себе оценок, рассчитанных по показателям внутренних процессов в банке, и оценочных показателей по вопросам, сформулированным специально для уточнения репутационного риска.

Рассмотрим первую часть методики:

На основе выбранной и проанализированной нами информации были выбраны факторы, которые более других оказывают влияние на деловую репутацию кредитной организации и, таким образом, способствуют увеличению уровня репутационного риска. В основном угроза деловой репутации кредитной организации исходит изнутри [10].

Предлагаемый методический подход к оценке уровня репутационного риска предполагает проведение внутренней проверки в коммерческом банке, в рамках которой должно проводиться выявление случаев, которые могут оказать существенное влияние на уровень репутационного риска банка. Исходя из этого было выбрано несколько направлений проверки: кредитование клиентов корпоративного блока банка, кредитование физических лиц и кассовые операции кредитной организации. Каждому выявленному в процессе проверки нарушению будет присваиваться оценка, при этом число случаев данного нарушения по определенной оценке суммируется. Градация оценок в рамках предлагаемой методики осуществляется следующим образом:

- исправлено (И) - выявленное нарушение в ходе проверки устранено и подтверждено документально (оценивается в 1 балл);

- просто (П) - выявленное нарушение достаточно легко исправимо и не требует дополнительных издержек. Срок исправления данного нарушения - не более 3 рабочих дней (оценивается в 2 балла);

- сложно (C) - нарушение довольно сложно исправить, в процессе исправления потребуются дополнительные затраты или согласованные действия группы работников, превышающих их обычные должностные обязанности. Срок исправления данного нарушения - не более 7 рабочих дней (оценивается в 3 балла);

- невозможно $(\mathrm{H})$ - нарушение невозможно исправить (оценивается в 4 балла).

Итоговая оценка уровня риска в баллах в рассматриваемых подразделениях банка выставляется на основе суммы баллов, получаемых в результате умножения числа нарушений (в зависимости от сложности и возможности их исправления), которые выявлены в ходе проведения проверки подразделений банка и бизнеспроцессов, на количество баллов, которым со- 
ответствует каждый уровень сложности исправления.

После можно рассчитать степень риска по каждому направлению проверки банка (например, кредитование юридических лиц, кредитование фризических лиц) банка. Для этого необходимо количество баллов по каждому направлению проверки разделить на общее количество баллов. Полученное процентное соотношению отнести к одной из степеней риска внутренних процессов банка.

\section{Определение степени риска внутри процессов банка}

Table 1. Determining the degree of risk within the bank processes

\begin{tabular}{|c|c|c|}
\hline Степень & Уровень риска & $\%$ \\
\hline I (первая) & Критичный & $81-100$ \\
\hline II (вторая) & Высокий & $51-80$ \\
\hline III (третья) & Средний & $31-50$ \\
\hline IV (четвертая) & Низкий & $1-30$ \\
\hline
\end{tabular}

Источник: составлено авторами на основе [2]. Source: compiled by the authors on the basis [2].

Примечания: I степень (критичный риск) нарушения критичны, могут привести к значительным рискам и убыткам для банка; II степень (высокий риск) - нарушения существенны, в процессах банка установлены недостатки, которые необходимо устранить; III степень (средний риск) - нарушения не столь сущест- венны, процессы, функционирующие в банке, находятся под постоянным контролем, возможные убытки или потери будут своевременно выявлены и предотвращены; IV степень (низкийриск) - нарушения не существенны. Данная схема определения степени репутационного риска и градация оценок риска взята из статьи Ю.А.Ким «Репутационные риски в сфере банковских услуг» и скорректирована в процентной градации уровня риска [2]. Что касается присвоения баллов градации оценок и разработки таблицы по определению баллов по каждому направлению проверки, то здесь данными разработками занимались авторы данной работы на основе проанализированной информации в научной литературе [11, 12].

Рассмотрим для наглядности показатели по 3 банкам: ПАО Сбербанк, ВТБ и АО КИБ «Евроальянс». При выборе банков для нас было важно сравнить, как относятся к управлению и оценке репутационным риском системнозначимые банки (ПАО Сбербанк и ПАО ВТБ) и небольшие региональные банки (в нашем случае АО КИБ «Евроальянс»). По нашему мнению, сравнивать такие банки по данной методике корректно, так как затрагивается вопрос не финансовых показателей, а именно отношение банков к своей репутации, их контроль и внимание к данной сфрере. Проанализировав полученные показатели, можно объединить их в таблицу 2 для наглядности.

Анализ итогов проверки коммерческих банков на наличие репутационного риска Table 2. Analysis of the results of checking commercial banks for reputational risk

\begin{tabular}{|c|c|c|c|c|c|c|}
\hline & \multicolumn{6}{|c|}{ Наименование банка } \\
\hline $\begin{array}{c}\text { Направление про- } \\
\text { верки }\end{array}$ & $\begin{array}{c}\text { ПАО } \\
\text { Сбербанк }\end{array}$ & $\begin{array}{c}\text { Степень } \\
\text { риска }\end{array}$ & ПАО ВТБ & $\begin{array}{c}\text { Степень } \\
\text { риска }\end{array}$ & $\begin{array}{c}\text { АО КИБ «Ев- } \\
\text { роальянс» }\end{array}$ & $\begin{array}{c}\text { Степень } \\
\text { риска }\end{array}$ \\
\hline $\begin{array}{c}\text { Кредитование кли- } \\
\text { ентов корпоратив- } \\
\text { ного блока банка }\end{array}$ & $20,18 \%$ & IV & $13,35 \%$ & IV & $22,32 \%$ & IV \\
\hline $\begin{array}{c}\text { Кредитование фи- } \\
\text { зических лиц в бан- } \\
\text { ке }\end{array}$ & $23,15 \%$ & IV & $23,43 \%$ & IV & $28,33 \%$ & IV \\
\hline $\begin{array}{c}\text { Кассовые операции } \\
\text { банка }\end{array}$ & $56,68 \%$ & II & $63,22 \%$ & II & $49,36 \%$ & III \\
\hline
\end{tabular}

Источник: составлено авторами с использованием статистических данных Банка России (http://www.cbr.ru).

Source: compiled by the authors using Bank of Russia statistical data (http://www.cbr.ru).

Сопоставляя данные в таблице с нормативами степени риска, можно сказать, что в ПАО Сбербанк и ПАО ВТБ два первых показателя из трех соответствуют низкому уровню риска, третий же показатель высокому уровню риска. Что касается АО КИБ «Евроальянс», то в этом банке первые два показателя соответствуют низкому уровню риска, а третий - среднему.
Можно предположить, что это связано с тем, что АО КИБ «Евроальянс» является небольшим региональным банком, который очень дорожит своей репутацией и много внимания уделяет стремлению к устойчивому положению среди других банков более крупных банков, что объясняет небольшое количеством критических ошибок, которые уже нельзя исправить при 
проверке [13]. Особенно это становится актуально при принятии закона о разделении кредитных организаций на банки с универсальной и базовой лицензиями.

Что касается ПАО Сбербанк и ПАО ВТБ, то данные банки можно отнести к сильнейшим банкам РФ, особенно Сбербанк. Эти банки большое значение придают финансовым показателям, в погоне за которыми могут совершать существенные ошибки. Они способны пренебрегать некоторыми внутрибанковскими правилами, что иногда может наоборот привести к необратимым последствиям.

Вторая часть методики - это ответы на список специально отобранных вопросов:

1) С какой частотой банк получает жалобы, претензий и судебные иски со стороны клиентов и контрагентов? Весовое значение вопроса -2 ;

2) С какой частотой к банку применяются меры воздействия (штрафы, предписания и т.д.) со стороны органов регулирования и надзора? Весовое значение вопроса - 3;

3) Присутствуют ли случаи несоблюдения 115 Ф3 «О противодействии легализации (отмыванию) доходов, полученных преступным путем, и финансированию терроризма"? Весовое значение вопроса - 3 ;

4) С какой частотой появляется негативная информация о банке, его сотрудниках, участниках, аффрилированных лицах в СМИ и Интернете? Весовое значение вопроса - 2;

5) Существуют ли фракты разглашения сотрудниками коммерческой, банковской и иной тайны, разглашения сведений, которые стали известны в силу исполнения своих служебных обязанностей? Весовое значение вопроса - 2;

6) Присутствует ли в банке повышенный уровень других рисков: кредитного, валютного, операционного, правового, потери ликвидности? Весовое значение вопроса - 2;

7) С какой частотой встречаются сотрудники банка с отсутствием высшего образования и квалификации? Весовое значение вопроса - 1;

8) С какой частотой встречаются факты несоблюдения банком условий по договорам? Весовое значение вопроса - 2 .

Вопросы подбирались исходя из важных моментов, которые существенно могут повлиять на уровень репутационного риска банка [14]. Некоторые вопросы взяты из Указания Банка России от 3 апреля 2017 г. № 4336-У "Об оценке экономического положения банков", некоторые подобраны исходя из проанализированной информации. Оценка ответов на вопросы производится путем присвоения им значений по трехбалльной шкале (разработана автором данной научной работы), на основе проанализированной информации в Указании Банка России от 3 апреля 2017 г. № 4336-У "Об оценке экономического положения банков"): равное 1 - "нет"("никогда", "ни в каких случаях");

равное 2 - "иногда";

равное 3 - "да" ("постоянно", "всегда", "в полном объеме")

Сам уровень риска рассчитывается по формуле:

$$
\sum_{i=1}^{8}[(\text { балл } i] \times \text { вес } i): \sum_{i=1}^{8} \text { вес } i
$$

Весовая оценка ответов на вопросы для определения показателя репутационного риска, которая присваивалась самими авторами данной научной работы исходя из важности вопросов, приведена выше. Например, мы посчитали, что вопрос, касающийся нарушения 115 Ф3 важнее и заслуживает вес 3, а появление негативной информации в СМИ менее важно событие и ему можно присвоить вес 2, так как, например, информация в СМИ может являться субъективным мнение автора, а федеральный закон - это нормативный правовой акт высшей юридической силы, принятый исключительно законодательным (представительным) органом государственной власти РФ (Федеральным Собранием) по предметам ведения РФ и ее субъектов либо принятый непосредственно народом путем всероссийского референдума.

Показатель должен быть приведен к целому числу. Если дробная часть показателя имеет значение меньше 0,45, то ему присваивается значение, равное его целой части. Если более 0,45 - показатель принимается равным его целой части, увеличенной на 1 .

равный 1 - хорошее;

равный 2 - удовлетворительное;

равный 3 - плохое.

Полученные данные сведем в общую таблицу (табл. 3).

Таблица 3

Анализ состояния ПАО Сбербанк, ПАО ВТБ, АО КИБ «Евроальянс»

Table 3. Analysis of the state of PJSC Sberbank, PJSC VTB, JSC KIB "Evroalyans"

\begin{tabular}{|c|c|c|}
\hline $\begin{array}{c}\text { Наименование } \\
\text { банка }\end{array}$ & Показатель & Состояние банка \\
\hline $\begin{array}{c}\text { ПАО Сбер- } \\
\text { банк }\end{array}$ & $28 / 17=1,64$ & удовлетворительное \\
\hline ПАО ВТБ & $29 / 17=1,71$ & удовлетворительное \\
\hline $\begin{array}{c}\text { АО КИБ «Ев- } \\
\text { роальянс» }\end{array}$ & $23 / 17=1,35$ & хорошее \\
\hline
\end{tabular}

Источник: составлено авторами с использованием статистических данных Банка России (http://www.cbr.ru).

Source: compiled by the authors using Bank of Russia statistical data (http://www.cbr.ru). 
Итоги по показателям получились примерно такие же, как и в первой части методики. Состояние банков по отношению к уровню риска в ПАО Сбербанк и ПАО ВТБ можно считать удовлетворительным, что касается АО КИБ «Евроальянс», то там состояние хорошее.

Это можно объяснить также небольшим размером банка, который борется за каждого своего клиента, тем самым отсюда почти нет негативной информации в СМИ, жалоб со стороны клиентов и партнеров, жесткая дисциплина, которая приводит к выполнению внутрибанковских правил [15]. В ПАО Сбербанк и ПАО ВТБ наоборот очень сложно уследить за всеми сотрудниками, всеми процессами внутри банка, так как на территории РФ огромное количество филиалов. Проблематично своевременно отвечать на все вопросы и недовольства со стороны клиентов из-за большого их количества, что приводит к негативной информации в СМИ. Однако это состояние можно объяснить тем, что такого вида банки уже заработали себе репутацию и от ухода нескольких клиентов они ничего не потеряют, хотя это глубокое заблуждение, которое может привести к серьезным проблемам.

Далее мы исследуем показатели, которые у нас получились после проведения анализа по двум частям. Полученные результаты характеризуют состояние системы управления репутационным риском, а, следовательно, и состояние устойчивости кредитной организации. Это объясняется тем, что ввиду специфики банковской деятельности, при которой около $90 \%$ активных операций совершается за счет средств, привлеченных от клиентов, деловая репутация будет являться не просто одним из видов нематериальных активов, а основным и необходимым условием сохранения деятельности на длительную перспективу.

Если в первой части мы получаем больше $65 \%$ показателей со степенью риска III и IV, а во второй части показатель равен 1 или 2, то устойчивость кредитной организации считается удовлетворительной. Если хотя бы один из критериев не выполняется (или оба), то устойчивости банка будет присвоен низкий уровень. (Данная методика оценки разработана авторами данной научной работы).

Таким образом, итоговыми показателями методики становятся определение уровня риска и оценка устойчивости кредитной организации. Как правило, если уровень репутационного риска имеет критические оценки, то и устойчивость банка находится под угрозой. Это связано с тем, что данные показатели тесно взаимосвязаны. Подытожив, можно сказать, что у всех трех банков уровень устойчивости считается удовлетворительным, но лучше все-таки она у АО КИБ «Евроальянс», что объясняется хоро- шей системой внутрибанковского контроля, умением построить работу сотрудников и постоянным поиском подходов к новым и уже действующим клиентам.

ПАО Сбербанк и ПАО ВТБ хочется пожелать более внимательно относиться к своим клиентам, ведь именно через них банк получает прибыль, соответственно наладить процессы внутри банка для слаженной работы на такой огромной территории с большим количеством филиалов и стараться не допускать критических ошибок [16, 17].

Проведенный анализ кредитных организаций показал, что неустойчивое положение и отзыв лицензий российских банков во многом связан с низким качеством менеджмента в целом и отсутствием четко проработанной стратегии управления деловой репутацией [18, 19, 20].

Таким образом, не стоит недооценивать влияние репутационного риска на устойчивость кредитной организации. Предложенный методический подход позволяет дать предварительную оценку влияния репутационного риска на устойчивость кредитной организации, поскольку данный риск непосредственно образом связан с реализацией событий, входящих в состав рыночных, операционных, фринансовых и прочих рисков банка, а значит и с ее устойчивостью. Использование предложенной методики в практической деятельности банка позволит выявить и своевременно устранить факторы, способствующие нарушению устойчивости банка. Управление репутационным риском должно стать полноценной составляющей частью системы управления рисками в целом в банке.

\section{Литература}

1. Кораблева О.Н. Репутационные риски в системе риск-менеджмента коммерческого банка // Российское предпринимательство. 2013. №24. C. 55-60.

2. Ким Ю.К. Репутационные риски в сфрере банковских услуг // Человеческий капитал и профессиональное образование. 2014. №2. C. 24-37.

3. Марамыгин М.С., Балин С.Е. О некоторых видах банковских рисков//Известия УрГЭУ 2014. - №6 - C.60-64

4. Гигеренцер Г. Понимать риски. Как выбирать правильный курс / Г. Гигеренцер. - Изд-во «КоЛибри», 2015. - 352с.

5. Печалова М.Ю. Банковские риски: распознание и методы оценки // Экономика. Бизнес. Банки. 2015. №2. С. 1-150.

6. Бикина И. Процесс слияний и поглощений как элемент эфффективной корпоративной стратегии // Проблемы теории и практики управления,2015. № 8. С. 76-84.

7. Восканян Р.О. Реализация стратегии роста стоимости инновационной компании посред- 
ством конгломератных сделок // Экономический анализ: теория и практика, 2015. № 1 (400). C. 54-60.

8. Вердиев Д. Повышение фринансовой эффрективности сделок слияний и поглощений международных холдинговых компаний // Управление риском, 2015. № 3 (75). С. 49-56.

9. Четверикова Е.А., Бибикова Е.А., Валинурова А.А. Методика оценки финансовой устойчивости региональной банковской системы// Финансы и кредит. 2017. Т. 23. № 20 (740). C. 1154-1172.

10.Селезнева Р. С. Организация рискменеджмента в банке // Экономика и управление: проблемы, тенденции, перспективы развития. 2016. № 1 С. 205-207.

11.Базилевич С.В., Легчилина Е.Ю. Количественные методы в управлении/ С.В. Базиличев, Е.Ю. Легчилина - М.: Москва-Берлин, 2015. - $86 \mathrm{c}$

12.Капустина Н.В. Теоретико-методологические подходы риск-менеджмента / Н.В. Капустина. - М.: Инфра-М, 2016. - 140 с.

13.Леонов М.В. Региональные банки в банковской системе России // Пространственная экономика. 2015. №2. С.116-131.

14.Киселева И.А., Симонович Н.Е. Оценка рисков с учетом влияния человеческого фактора // Экономический анализ: теория и практика. - 2014. - № 2 (353) - С. 21-27.

15.Бисултанова А.А. Региональные банки в современных условиях экономики России // Финансы и кредит. 2016. Т. 22. №24 (696). С. 17-25.

16.Джаксыбекова Г.Н., Нургалиева А.М. Банковский риск-менеджмент // Рискменеджмент в коммерческом банке. 2015. № 3. C. 2.

17.Печалова М.Ю. Организация рискменеджмента в коммерческом банке // Менеджмент в России и за рубежом. 2015. № 1. С. 3-15.

18.Валдайцев С.В. Оценка бизнеса / С.В. Валдайцев . - 3-е изд., перераб. и доп. - М.: ТК «Велби», Изд-во «Проспект», 2008. 360 с.

19.Мазгунова Н.В., Федотов В.Д. Управление рисками в коммерческих банках // Научный вестник ЮИМ. 2018. № 3. С. 68-73.

20.Денисова Н.И., Чиженко Л.М. К вопросу о современных подходах к управлению фринансовыми рисками коммерческих банков // Вестник Московского университета имени С.Ю. Витте. Серия 1: Экономика и управление. 2017. № 1(20). С. 80-83.

21.Басалдук А. С., Езангина И.А. Репутационный риск банка: проблемы идентификации и управления// Сборник статей XIII Международной научно-практической конференции: в 2 частях. Том. Часть 2. 7.12.2017.

22.Исмагилов А.Н., Дубова С.Е. Проблемы и перспективы банков с иностранным участи- ем в российской банковской сфере// Известия высших учебных заведений. Серия: Экономика, финансы и управление производством. 2018. № 4 (38). С. 7-15.

\section{References}

1. Korableva O.N. Reputational risks in the risk management system of a commercial bank. Russian business, 2013. N 24. pp. 55-60 (in Russian).

2. Kim Yu.K. Reputational risks in banking services. Human capital and vocational education. 2014. N 2. pp. 24-37 (in Russian).

3. Maramygin M.S., Balin S.E. About some types of banking risks. News of the USUE. 2014. N 6.pp.60-64 (in Russian).

4. Gigerentser G. Understand the risks. How to choose the right course. «KoLibri» Publ., 2015.352 p. (in Russian).

5. Pechalova M.Yu. Banking Risks: Recognition and Evaluation Methods. Economy. Business.Banks.2015. N 2.pp. 1-150 (in Russian).

6. Bikina I. Implementation of the strategy of growth of value of an innovative company through conglomerate transactions. Problems of theory and practice of management, 2015. N 8. pp. 76-84 (in Russian).

7. Voskanyan R.O. Implementation of the strategy of growth of value of an innovative company through conglomerate transactions. Economic analysis: theory and practice, 2015. N 1 (400). pp. 54-60 (in Russian).

8. Verdiev D. Improving the financial efficiency of mergers and acquisitions of international holding companies. Risk management, 2015. N 3 (75). pp. 49-56 (in Russian).

9. Chetverikova E.A., Bibikova E.A., Valinurova A.A. Methods of assessing the financial sustainability of the regional banking system. Finance and credit. 2017. Vol. 23. N 20 (740). pp. 1154-1172 (in Russian).

10.Selezneva R. S. Organization of risk management in the bank. Economics and Management: problems, trends, development prospects. 2016. N 1 pp. 205-207 (in Russian).

11.Bazilevich S.V., LegchilinaE.Yu. Quantitative methods in management. Moscow. MoskvaBerlin Publ., 2015. - 86 p. (in Russian).

12.Kapustina N.V. Theoretical and methodological approaches of risk management. Moscow. Infra-M Publ., 2016.140 p. (in Russian).

13.Leonov M.V. Regional banks in the Russian banking system. Spatial Economics. 2015. N 2.pp.116-131 (in Russian).

14.Kiseleva I.A., Simonovich N.E. Risk assessment taking into account the human factor. Economic analysis: theory and practice.2014. N 2 (353).pp. 21-27 (in Russian).

15.Bisultanova A.A. Regional banks in the modern Russian economy. Finance and credit. 2016. T. 22. N 24 (696). pp. 17-25 (in Russian). 
Известия ВУЗов. Серия «Экономика, финансы и управление производством»

16.Dzhaksybekova G.N., Nurgalieva A.M. Banking Risk Management. Risk management in a commercial bank.2015. N 3.p. 2 (in Russian).

17.PechalovaM.Yu. Organization of risk management in a commercial bank. Management in Russia and abroad. 2015. N 1. pp. 3-15 (in Russian).

18. Valdaytsev S.V. Business valuation. Moscow. TK «Velbi», «Prospekt» Publ., 2008. 360 p. (in Russian).

19. Mazgunova N.V., Fedotov V.D. Risk management in commercial banks] Scientific Herald of the SIM. 2018. N 3.pp. 68-73 (in Russian).

20.Denisova N.I., Chizhenko L.M. On the issue of modern approaches to managing financial risks of commercial banks. Bulletin of the Moscow
University named after S.Yu. Witte. Series 1: Economics and Management. 2017. N 1(20). pp. 80-83 (in Russian).

21.Basalduk A. S., Ezangina I. A. Reputational risk of the bank: problems of identification and management // «EUROPEAN RESEARCH», 07.12.2017.

22.Ismagilov A. N., Dubova C. E. The problems and prospects of banks with foreign participation in the russian banking sector // "News Of Higher Educational Institutions. A Series «Economy, Finance And Production Management» 2018. № 4 (38). p. 7-15.

\section{АЛГОРИТМ ОРГАНИЗАЦИИ ФИНАНСОВ ГОСУДАРСТВЕННОГО СЕКТОРА}

Макашина Ольга Владиленовна, Красникова Наталия Сергеевна

Финансовый университет при правительстве Российской Федерации, Ленинградский просп., 49, Москва, 125993, Россия

E-mail: OVMakashina@fa.ru,nkrasnikova@fa.ru

Целью исследования являлось выделение причин, по которым возникла необходимость формирования новой модели финансов государственного сектора и разработка алгоритма организации финансов государственного сектора. Проведено сравнение положений, разработанных международным валютным фондом руководств, посвященных вопросам статистики государственных финансов. Авторы исходили из положений руководств о том, что исходной точкой организации финансов государственного сектора стала идентификация институциональных единиц и видов деятельности, которые относятся к государственному сектору. Это и позволило определить состав финансов государственного сектора. Целью организации финансов государственного сектора является удовлетворение социально-экономических потребностей общества, обеспечение соблюдения надлежащего уровня национальной безопасности. Необходимость функционирования институциональных единиц государственного сектора связана с тем, что на чисто предпринимательской основе было бы невозможно удовлетворить общественные потребности. Определено, что практическое применение принципов классификации секторов потребуется в случаях, когда необходимо выяснить относится тот или иной субъект к институциональным единицам и, если да - к какому именно сектору (либо к сектору государственного управления, либо к государственным корпорациям). В работе показано, что с точки зрения влияния на налогово-бюджетную политику к финансам государственного сектора относятся финансы сектора государственного управления, состоящего в свою очередь из институциональных единиц, которые заняты преимущественно нерыночной деятельностью и финансы государственных корпораций (организаций). Предложенный подход к организации финансов государственного сектора на основе концепции институциональных единиц позволит повысить доступность ключевых статистических данных. Это безусловно соответствует стремлению большинства стран к повышению прозрачности и подотчетности в общественном секторе. Кроме того, способствует выявлению недостатков на ранних этапах ухудшения финансовой ситуации в стране и своевременному принятию коррективных мер.

Ключевые слова: государственное управление, государственный сектор, налогово-бюджетный анализ, институциональная единица, государственные корпорации 